\title{
CRITICAL REVIEW OF GRANULOMATOUS MASTITIS
}

\author{
Ambujam Govindasamy1, Bharathidasan Rajamanickam², Raj Prakash Chandramohan ${ }^{3}$ \\ 1 Professor and HOD, Department of Surgery, Vinayaka Mission's Medical College. \\ ${ }^{2}$ Associate Professor, Department of Surgery, Vinayaka Mission's Medical College. \\ 3Postgraduate Student, Department of Surgery, Vinayaka Mission's Medical College.
}

\begin{abstract}
BACKGROUND

The clinical manifestations, imaging and pathological findings though typical are closely mimicking other specific granulomatous types like tuberculosis; mycotic the treatment for this condition needs to be carefully planned in the initial stage itself. This will resolve the psychological issues and prevent recurrence. The study includes 30 cases of granulomatous mastitis belonging to varying age groups, social status, parity and menopausal status. The diagnostic workup is mainly in the form of imaging and histopath ological in close correlation with clinical findings, helped us to treat the patients effectively. The treatment modalities offered, results and followup are tabulated.

The purpose of this study is to present the author's experience by their critical clinical analysis based on aetiopathological and imaging modalities and to formulate effective treatment modalities in granulomatous mastitis.
\end{abstract}

\section{MATERIALS AND METHODS}

The study was conducted in Vinayaka Mission's Medical College, Karaikal and Private Clinic in Thanjavur; 30 patients diagnosed as granulomatous mastitis were divided into 4 groups based on the treatment modalities offered to them; conservative antimicrobial therapy for 3 cases. Surgical drainage and/or surgical wide local excision in 27 cases.

\section{RESULTS}

Antimicrobial therapy after culture and sensitivity was given for 3 cases, out of which 1 case had improvement and drainage procedure was carried out in another case followed by excision for antibioma and the other case was lost to followup. Wide local excision was carried out in 27 patients, out of which 24 were cured, 2 patients had delayed healing and 1 patient was lost during followup.

\section{CONCLUSION}

Granulomatous mastitis is an inflammatory breast disease found in young women who present with a large painful irregular mass, which mimics carcinoma as a physical change. The correct diagnosis is established by cytological or histological examination. Granulomatous mastitis is a benign problem, but if not treated effectively and adequately life would be miserable with a chronic nonhealing and multiple sinuses.

\section{KEYWORDS}

Granulomatous Mastitis, Treatment.

HOW TO CITE THIS ARTICLE: Govindasamy A, Rajamanickam B, Chandramohan RP. Critical review of granulomatous mastitis. J. Evolution Med. Dent. Sci. 2016;5(101):7435-7437, DOI: 10.14260/jemds/2016/1683

\section{BACKGROUND}

Granulomatous mastitis is an uncommon benign lesion of the breast and has distinct clinical, imaging and pathological characters. ${ }^{1}$ Most of the times if not critically analysed and observed, it may even lead to a disastrous decision of malignancy since imaging and pathology closely mimics malignancy.

The condition is thought to be autoimmune and illunderstood and so labelled also as idiopathic granulomatous mastitis by some authors. Treatment options are observation after cytology, antimicrobial therapy after antibiogram which

Financial or Other, Competing Interest: None.

Submission 14-10-2016, Peer Review 05-12-2016,

Acceptance 13-12-2016, Published 19-12-2016.

Corresponding Author:

Dr. Ambujam Govindasamy,

Professor \& HOD,

Department of Surgery,

Vinayaka Mission's Medical College and Hospital,

Karaikal-609609.

E-mail: ambujam19@gmail.com

DOI: $10.14260 / j e m d s / 2016 / 1683$ is unsatisfactory in $90 \%$ of occasions and residual lesions need surgical intervention to rule out malignancy and if it is confirmed $100 \%$ as benign beyond doubt, then the patient has to be reassured.2,3,4 So effective treatment modality depends upon the skill and experience of the surgeon, time of onset of the problem and presentation to the consultant and previous treatments given. 2,5

\section{MATERIALS AND METHODS}

30 patients diagnosed as granulomatous mastitis were divided into 4 groups based on the treatment modalities offered to them. Conservative antimicrobial therapy for 3 cases. Surgical drainage and/or surgical wide local excision in 27 cases.

The present study includes 30 female patients in the age group of 20 to 53 years tabulated as follows.

\begin{tabular}{|c|c|c|c|c|c|}
\hline \multirow{2}{*}{ Age } & \multirow{2}{*}{$\begin{array}{l}\text { No. of } \\
\text { Cases }\end{array}$} & \multicolumn{2}{|c|}{ Prior Treatment } & \multicolumn{2}{|c|}{ Marital Status } \\
\hline & & Yes & No & Yes & No \\
\hline $20-30$ & 5 & 3 & 2 & 5 & Nil \\
\hline $31-40$ & 17 & 12 & 5 & 17 & Nil \\
\hline $41-53$ & 8 & 7 & 1 & 8 & Nil \\
\hline \multicolumn{6}{|c|}{$\begin{array}{l}\text { Table showing Prior Treatment } \\
\text { and Marital Status of Patients }\end{array}$} \\
\hline
\end{tabular}


All the 30 cases were treated by the authors personally in their private or teaching institution from 2009 to March 2015 and the diagnostic and treatment protocols were analysed individually after careful clinical examination, imaging modalities like ultrasonogram, mammogram and in difficult cases MRI to delineate the lesion prior to surgery to avoid mastectomy. ${ }^{6}$

All the thirty cases had histological confirmation as granulomatous mastitis before instituting definitive treatment.

Patients were labelled as cured of the disease after a disease free interval of minimum one year. Follow-up period ranges from 1 to 7 years.

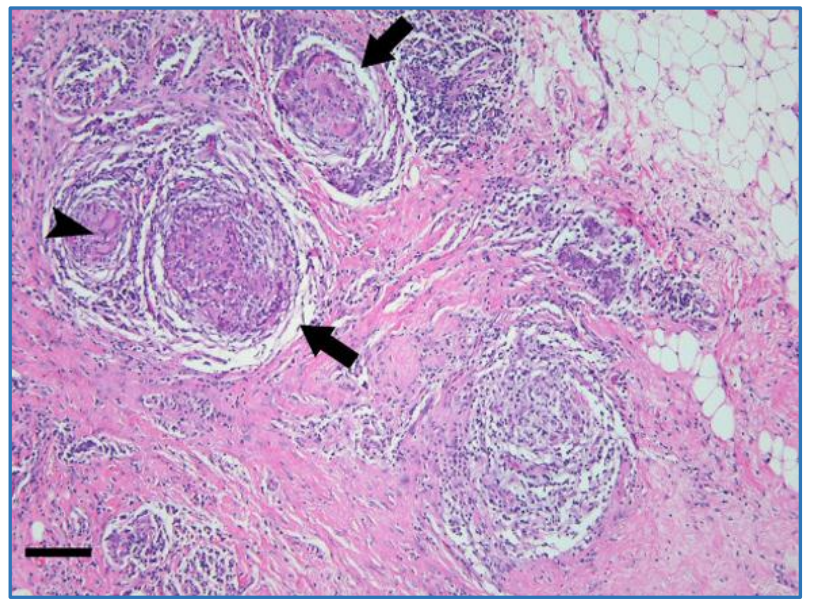

Figure 1. Arrows Indicate Granulomatous Inflammation Centered on Breast Lobules, While Arrowhead Indicates the Presence of Multinucleated Giant Cells within Non-Caseating Granulomatous Inflammation 4

Out of 30 female patients, 26 were in reproductive age and 4 were in menopausal age group.

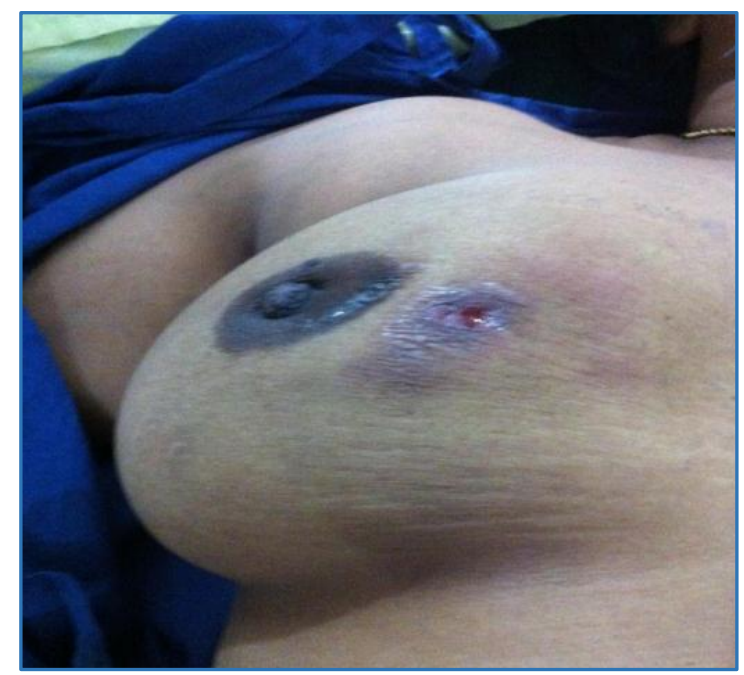

Figure 2. Pre-Op Pic of Granulomatous Mastitis

\begin{tabular}{|c|c|c|}
\hline Sl. No. & Types & No. of Cases \\
\hline 1. & $\begin{array}{c}\text { Non-Specific or } \\
\text { idiopathic }\end{array}$ & 17 \\
\hline 2. & $\begin{array}{c}\text { Pyogenic granulomatous mastitis } \\
\text { clinically diagnosed as antibioma }\end{array}$ & 13 \\
\hline \multicolumn{2}{|c|}{ Diagnostic Criteria for Granulomatous Mastitis } \\
\hline
\end{tabular}

\begin{tabular}{|c|c|c|}
\hline $\begin{array}{c}\text { Sl. } \\
\text { No. }\end{array}$ & Presentation & $\begin{array}{c}\text { No. of } \\
\text { Cases }\end{array}$ \\
\hline 1. & Breast Mass & 30 \\
\hline 2. & Painful Discharging Lesions & 27 \\
\hline 3. & Recurrent Mass & 22 \\
\hline 4. & $\begin{array}{c}\text { Multiple Sinuses with Undiagnosed } \\
\text { Mass after Initial Treatment }\end{array}$ & 15 \\
\hline \multicolumn{3}{|c|}{ Clinical Presentation } \\
\hline
\end{tabular}

\begin{tabular}{|c|c|c|}
\hline Sl. No. & Modalities & No. of Cases \\
\hline 1 & Mammogram with USG & 30 \\
\hline 2 & Core Needle Biopsy & 30 \\
\hline 3 & MRI & 3 \\
\hline \multicolumn{2}{|c|}{ Diagnostic Methods } \\
\hline
\end{tabular}

\section{RESULTS}

Antimicrobial therapy after culture and sensitivity was given for 3 cases, out of which 1 case had improvement and drainage procedure was carried out in another case followed by excision for antibioma and the other case was lost to followup.

Steroid and immunosuppression therapy were not contemplated in this series due to its limitation for success as per author's experience.

\section{Excision Biopsy}

This modality was instituted in all 27 patients, since 24 patients have had earlier conservative treatment or incision drainage elsewhere, but presented with residual or recurrent lesion mostly with multiple discharging sinuses in the breast.

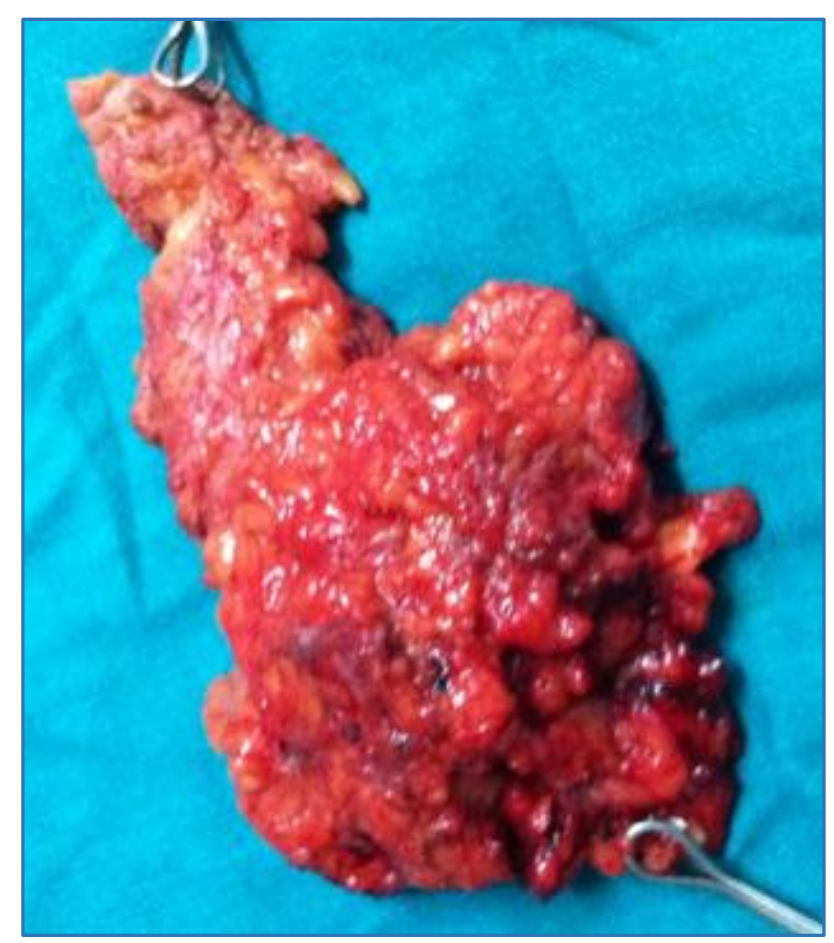

Figure 3. Post-Op Specimen after Wide Local Excision of Granulomatous Mastitis

\section{Wide Local Excision}

Wide local excision was carried out in 27 patients out of which 24 were cured, 2 patients had delayed healing and 1 patient was lost during followup. 


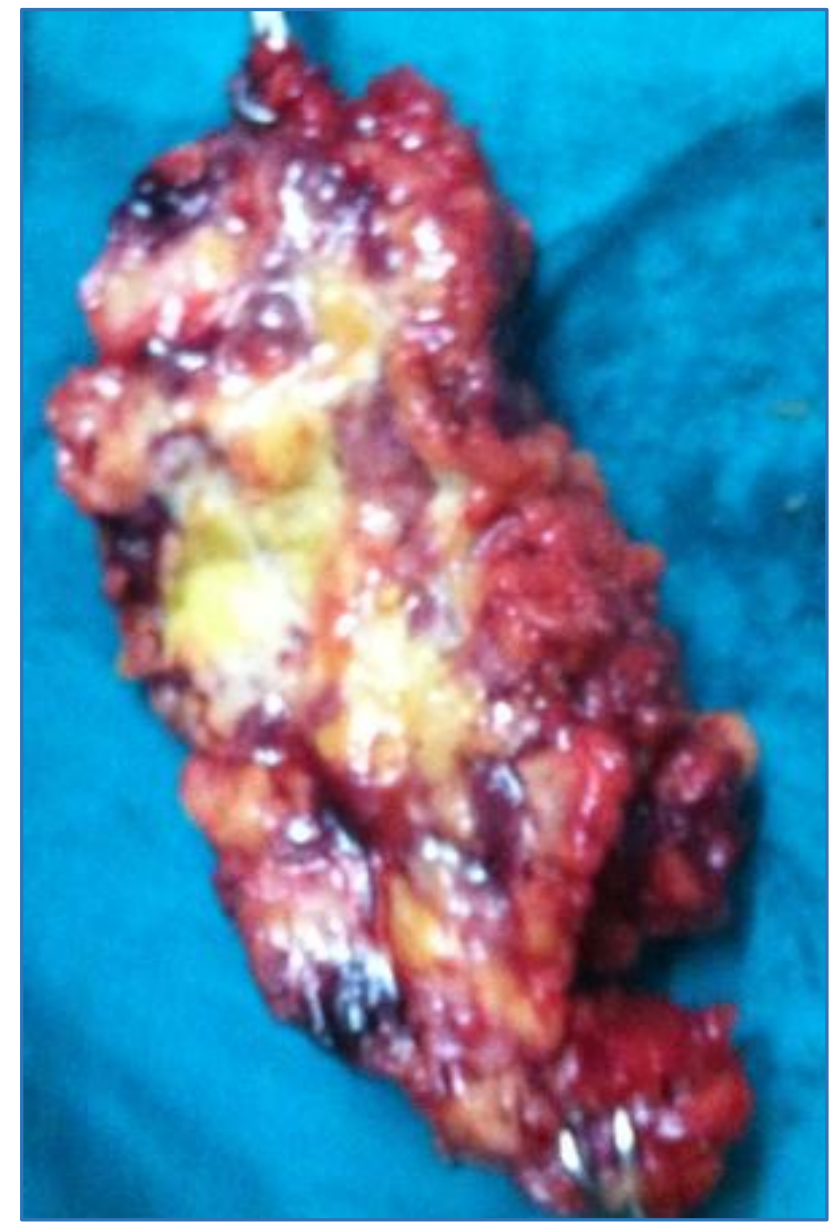

Figure 4. Specimen of Granulomatous Mastitis

\section{DISCUSSION}

Granulomatous mastitis, although less common, its aetiology definite and concrete management protocol is yet to be answered. Originally described by Kessler and Wolloch in 1972, it is characterised by the presence of epithelioid and multinucleated giant cell granulomas limited to the mammary lobules with micro-abscesses in the absence of obvious aetiology. $7,8,9$ Undoubtedly, it is a benign problem, but if not treated effectively and adequately life would be miserable with a chronic non-healing and multiple sinuses. ${ }^{10}$ It is an autoimmune disease and has distinct pathological picture. Surgical wide local excision is the gold standard treatment of choice and offers complete cure.5,6,11 On no occasion, the authors here encountered malignancy in this series.

Accurate delineation of the mass is of paramount importance before contemplating surgery to give complete cure after wide local excision 2,$11 ; 98 \%$ cure rate was possible in the present study.

\section{CONCLUSION}

Granulomatous mastitis is an inflammatory breast disease found in young women who present with a large painful irregular mass, which mimics carcinoma as a physical change. The correct diagnosis is established by cytological or histological examination. Medical treatment with corticosteroids provides significant regression of the inflammatory disease allowing more conservative surgery. ${ }^{12}$ Consecutive surgical excision of the remaining lesions with good cosmetic results provides definitive treatment and reduces the risk of recurrence. 8,11

\section{REFERENCES}

1. Lee $\mathrm{JH}, \mathrm{Oh} \mathrm{KK}, \mathrm{Kim} \mathrm{EK}$, et al. Radiologic and clinical features of idiopathic granulomatous lobular mastitis mimicking advanced breast cancer. Younsei Med J 2006;47(1):78-84.

2. Kim J, Tymms KE, Buckingham JM. Methotrexate in the management of granulomatous mastitis. ANZ J surg 2003;73(4):247-9.

3. Wilson JP, Massoll N, Marshall J, et al. Idiopathic granulomatous mastitis: in search of a therapeutic paradigm. Am Sarg 2007;73(8):798-802.

4. Kim YZ, Choi YJ, Kim YJ, et al. Clinicopathological features of granulomatous mastitis. Korean $J$ pathol 2005;39(3):181-6.

5. Bani-Hani KE, Yaghan RJ, Matalka II, et al. Idiopathic granulomatous mastitis: time to avoid unnecessary mastectomies. Breast J 2004;10(4):318-22.

6. Alkhaffaf B, Knox F, Bundred NJ. Idiopathic granulomatous mastitis: a 25-years experience. J Am Coll Surg 2008;206(2):269-73.

7. Heer R, Shrimankar J, Griffith CD. Granulomatous mastitis can mimic breast cancer on clinical, radiological or cytological examination: a cautionary tale. Breast 2003;12(4):283-6.

8. Tae SY, Lee SW, Han SU, et al. Surgical treatment for idiopathic granulomatous mastitis. J Korean surg soc 2009;77(3):153-60.

9. DeHertogh DA, Rossof AH, Harris AA, et al. Prednisone management of granulomatous mastitis. N Engl J Med 1980;303(14):799-800.

10. Raj N, Macmillan RD, Ellis IO, et al. Rheumatologists and breast: immunosuppressive therapy for granulomatous mastitis. Rheumatology (oxford) 2004;43(8):1055-6.

11. Erozgen F, Ersoy YE, Akaydin M, et al. Corticosteroid treatment and timimg of surgery in idiopathic granulomatous mastitis confusing with breast carcinoma. Breast Cancer Res Trest 2010;123(2):447-52.

12. Sato N, Yamashita H, Kozaki N, et al. Granulomatous mastitis diagnosed and followed up by fine needle aspiration cytology, and successfully treated by corticosteroid therapy: report a case. Surg Today 1996;26(9):730-3. 